\title{
MAKING SENSE OF TOURISM TEACHING
}

\author{
Dimitrios Stergiou \\ Hellenic Open University, Greece \\ David Airey \\ Michael Riley \\ University of Surrey, UK
}

\begin{abstract}
This paper gives details about a study into the evaluation of tourism teaching in higher education. Although there has been a rapid growth in research into tourism education, little has focused on teaching or its evaluation. The work draws on literature from the field of education more generally to arrive at a set of dimensions. Based on these it explains a study conducted in the United Kingdom. Findings suggest that the important dimensions relate to the extent to which teaching is linked both to the vocational aspects as well as to deeper sets of experiences. Keywords: teaching evaluation, tourism education, student survey
\end{abstract}

Dimitrios Stergiou is Associated Academic at the Hellenic Open University (School of Social Science, Patras 26222, Greece. Email<dstergiou@eap.gr>). David Airey is Professor of Tourism Management and Pro-Vice-Chancellor at the University of Surrey. Michael Riley is Professor of Organizational Behavior in the same institution. Their combined research interests include connections between tourism and education, employment, and aspects of consumer behaviour and management. 


\section{INTRODUCTION}

Although there has been considerable emphasis in current research on developing a systematic and rigorous body of knowledge about tourism, it is noteworthy that remarkably little attention has been given to the conduct of teaching itself. Few researchers have participated in codifying what we know. This despite the fact that the activity constitutes an integral part of education. It is within the context of teaching that the curriculum is interpreted and acted upon and where the link between students and institutions is created and provided. These fundamental assumptions have led most researchers to subscribe to the assertion that research on education depends most heavily on research about teaching for its advancement (Winne and Marx 1977). This suggests that by ignoring the significant contributions that such knowledge can make to the field, the body of research remains incomplete.

This missing element has not gone unnoticed. For example, in his review of research trends, Tribe observes "How to teach has been overshadowed by what to teach and issues of effective teaching and assessment have been overlooked" (2002a:73). These comments were written in 2002. Since then the position has not changed. Of course, this missing element could, to a certain extent, be compensated by drawing on information from the extensive literature that relates to education in general; yet little use has been made of this.

This lack of attention may stem from an instrumentalist view of a fairly straightforward process of transmitting skills that will equip individuals for effective economic functioning in the industry (Airey 2005). Indeed, empirical evidence suggests that provision of courses is mainly being framed as a vocational one, dominated by business, managerial and instrumental aims (Airey and Johnson 1998, 1999, 2000). This is not to deny the relevance and usefulness of such provision but there are also other angles that deserve attention and can strengthen the provision.

This instrumental view can be summarized as, the transmission of skills in as causally efficient and effective a way as possible. This highlights the technical aspects in relation to which teachers' capacity for rational deliberation - for conceiving purposes, devising plans, or adopting means to ends in the light of knowledge - though important, is nevertheless secondary (Nykiel 1999). However, teaching involves more than the application of a number of practical skills - it also requires a wider range of human qualities and dispositions (Carr 1994). It is not just a matter of routine methods but a whole approach in which teachers use subtle styles and approaches to engage with their students. In light of this view, there is also a 
teleological dimension to the explanation which does not appear to be entirely eliminable in favor of functionalist accounts.

There is a second related problem. This relates to the fact that current conceptions fail to understand the educational character of teaching; for whatever else, it is an educative process. Carr has caught the essence of the point made here:

"Education is not merely a matter of 'delivering' an optimum curriculum in some quasi-technical sense but of the exercise of certain intellectual virtues. It is a shallow and false view of education and teaching which takes it to be a matter of the technical transmission of pre-packaged knowledge and skills in the context of efficient management" (1994:49).

A key task of this paper, therefore, is to spell out its features as an educative process. Accordingly, alongside the instrumentalist approach there is what is referred to here as an educational approach. This is important for the future development of tourism both as a serious field of scholarly endeavor and for the understanding in practice because without a broad understanding a key dimension is missing. Over the past few decades, knowledge about tourism has been developed rapidly, notably through the work of social scientists. The work of Cohen (1972), MacCannell (1973, 1976), Smith (1977), Graburn (1983) and Urry (1990) in sociology and anthropology, of Butler (1980) and Pearce (1987) from the geographical perspective, Archer (1977) as an economist as well as Tribe (1997) from the viewpoint of the field itself has marked the initial contributions to a flow of studies that now provide a strong framework for analyzing and understanding. In turn, this work has been brought into textbooks (Holden 2005; Tribe and Airey 2007) for ready access to students. This provides the basis for tourism in the classroom to expand well beyond its vocational boundaries. But, if, in the meantime, in actual activities in the classroom an instrumental and business approach remains dominant this can act as a brake on the extent to which this is brought into full effect. Insufficient interaction between teaching and knowledge sets limitations to the contribution of those who are studying. This is relevant at all levels, from operatives to those aiming at the highest positions. It is also relevant in all contexts. Indeed, in parts of the developing world a better understanding of what happens in the classroom could be the key for the better stewardship of the world's scarce resources.

There are, then, a set of considerations which justify the idea of teaching tourism as worthy of attention in its own right. It poses special problems of its own and it deserves 
special treatment simply because it is special. What will be attempted in this paper, therefore, is an investigative approach. It is an approach that takes its bearings from a sense of the complex character of teaching and places it in the center stage. More specifically, the overall aim of the paper is to explore the key dimensions on which it can be evaluated and, with reference to the views of students, to identify the main factors that are associated with good performance by teachers. Following an outline of the key dimensions, namely teaching ability and teacher knowledge, the paper describes the process of a Q-study that generated a total of 60 statements that provided the basis for a questionnaire survey from which the main factors are identified.

\section{MAKING SENSE OF TEACHING}

The preceding comments have suggested that there is little sense of educational direction in current discussions. The nature of the evaluation process and the underpinning concepts are under-theorized. For example, a study by Mount and Sciarini (1999) has proposed a set of evaluative performance criteria, but with no discernible theoretical underpinning. Against this background the starting point has to be the establishment of an investigative framework. In the absence of directly related literature this work draws upon studies of teaching in general particularly those developed over the past twenty years. This is not to deny the relevance of more contemporary work, rather it points to the need initially to set the study in the context of some of the fundamental thinking developed over the past few years in higher as well as other levels of education. This has mainly focused on the study of student ratings of instruction, on the ways teachers organize and manage learning activities, and on teacher's own conceptions (Cashin 1995; Centra 1994; Marsh 1987; Ramsden 1991). There are of course some important differences between higher and other levels of education, not least in the extent to which they draw on research and new knowledge and in the maturity of the participants. However, notwithstanding these differences, the work at other levels provides valuable starting points for understanding.

The development of the framework that follows has its roots in a number of key sources including Fenstermacher (1986), Shulman (1987), Squires (1999) and Wilson, Shulman and Richert (1987), among others. The discussion is structured around the following two propositions: that dimensions should be introduced as evaluative elaborations on the generic concept; that there exists a basic dichotomy in the dimensions on which teachers vary, corresponding generally to their understanding of what is to be taught and how it is to be taught. 
As far as evaluation is concerned, it is important to distinguish between the generic meaning and its elaborated forms. In fact, this issue was one of Jackson's (1986) prime concerns. He raises the question as to whether it is possible to define teaching in a way that speaks of its true meaning or essence without also becoming entangled in its appraisal. The main point of this analysis is to present an argument regarding the content, character, and dimensions. The question that focuses the argument is one posed by Hirst (1973:5): how do we distinguish it from other activities? The work of Fenstermacher (1986:38) on the different methods for its research provides a helpful way to initiate this analysis. He sets forth what he calls "The Generic Conditions" as follows: there is a person, $\mathrm{P}$, who possesses some content, c, and who intends to convey or impart c to a person, $\mathrm{R}$, who initially lacks $\mathrm{c}$, such that $\mathrm{P}$ and $\mathrm{R}$ engage in a relationship for the purpose of R's acquiring $\mathrm{c}$.

Returning to the original question (how do we distinguish teaching from other activities?), one answer is that a teacher possesses some knowledge or other content not understood by others and he or she intends to convey this content to them leading to the formation of a relationship for this purpose. In doing so, the tasks include selecting the content to be learned, adapting the material to the level of the students, helping them to get access to the content. Therefore, it necessarily begins with understanding of what is to be taught and how it is to be taught (Shulman 1987). It is important to note that learning itself cannot be fully attributed to teaching. It also remains the responsibility of the students.

This last point bears a bit more exploration. It could be argued that in order for $\mathrm{P}$ to be teaching at all, $\mathrm{R}$ must acquire what $\mathrm{P}$ is teaching. But this is to confuse the generic conditions with what might be called the appraisal conditions. As Fenstermacher has put it, "it makes no more sense to require learning in order to be teaching than it does to require winning in order to be racing, or finding in order to be looking" (1986:38). Clearly, given its purpose there must be a relationship with learning (Squires 1999). However, it is important to remember that learning goes on all the time, whether people are being taught or not. Indeed, there is now widespread evidence that the learning that goes on within the confines of formal education is only the visible tip of a much larger iceberg (Brockett and Hiemstra 1991; Candy 1991).

The characteristics listed above constitute a generic meaning. It follows that any additions to these conditions are elaborations. There are many forms of such elaboration. So for example, researchers concerned with what might be called the appraisal conditions make evaluative elaborations of what is good and what is poor. The implication here is that the generic conditions provide a theoretical framework that will allow empirical questions related 
to the evaluation to be formulated. The thrust of the argument here lies in the assumption that an adequate conceptualization needs to be developed before tackling the evaluative issues (Squires 1999).

Having established the relationship between the ontology and the evaluation, the focus of the discussion now turns to the two basic questions: What is to be taught? How is it to be taught? The first question relates to content. The word "content" is ambiguous. It can refer to everything that the student experiences or it can refer more narrowly to the subject matter (Squires 1999). It is being used in the latter sense here. This follows the thinking of Dunkin and Biddle (1974), who suggest that the content ought not be viewed as a context variable, comparable to class size or classroom climate, but should occupy a prominent position.

Central to any discussion of content - the subject matter of a course - is the academic unit responsible. The thrust of the argument is based on the assumption that a teacher should possess a certain minimum facility with, and understanding of, the subject to be taught (Wilson et al 1987). This then raises the question: what is essential for an individual teaching tourism? This inquiry into the nature of knowledge involves some epistemological questions: How is this organized? What forms does it take? What are the sources of information?

What is important here is that the teacher has special responsibilities in relation to subjectknowledge (Smith 1983). This responsibility places special demands not only on the depth, but also on the understanding of how it should be ordered in ways that will be clear and accessible (Shulman 1987). As noted, the knowledge has developed rapidly over the past few decades to the point where there is no shortage. The issue is how it is organized and presented to make sense in the classroom. It is obviously here that the need for understanding comes to the fore.

This analysis opens up the wider discussion concerning methods and techniques. The point of concern is what is actually meant by a teaching method: a term usually associated with the ways of going about the activity. It refers to all forms of hardware and software that teachers have at their disposal and the methods and techniques for using them (Squires 1999). It is in this sense that it is possible to speak of methods as procedural, in that a teacher is always concerned with and involved in going about things and doing things. The word procedural is being used here not only to mean identifiable operations but also to capture subtler and less explicit ways, styles and approaches. As Squires (1999) argues, the point about methods is that they need to be tailored to situations which are not wholly routine. They thus connote not just a particular technique (e.g. group work) but also a whole approach and it is in this sense that the term is used here. 
While the discussion may seem to have come a long way from the initiation of this analysis, the underlying point is still the same. The means and forms both structure and color perceptions of the whole activity. A teacher's understanding of what is to be taught is entangled with how they teach it. This basic split in thinking about the activity was built into the present study in the form of two major dimensions: teacher knowledge and teaching ability. These provide the basis on which the investigation rests. The importance of this here is that to date so little attention has been given to understanding these basic elements. Without a better appreciation, the potential for education to make a full contribution to the development of those who will be taking decisions about the future will be diminished.

\section{Study Methods}

Having identified ability and knowledge the starting point was to establish common dimensions by which these could be evaluated. This began with Q-methodology and then went on to use other statistical techniques and ideas, an effort based mainly on Fisher's ideas of correlation. Now more than half a century old (Stephenson 1953), Q-methodology is hardly a new method for conducting research. Indeed, the literature contains more than 1500 bibliographic entries on Q-studies across the social sciences (McKeown and Thomas 1988). Notwithstanding, Q retains a somewhat fugitive status within the larger social scientific community. This can perhaps be explained by noting that whereas most social scientists have at least heard of Q-methodology, only a handful have attended seriously to its broader methodological foundations and principles (Brown 1986).

Q-methodology provides researchers with a systematic and orderly means for identifying the dimensions of subjective phenomena from the viewpoints and experiences of individuals (Stephenson 1953). It endeavours to convert subjective responses into measurable dimensions. By thus rendering the study of human subjectivity amenable to "objective" analysis, Q represents one of the few efforts to combine the strengths of both quantitative and qualitative research paradigms (Sexton, Snyder, Wadsworth, Jardine and Ernest 1998). This very versatile procedure is especially suited to cases where the very existence of concepts has not been established (Ekinci and Riley 2001). Evaluation of teaching comes into this category. There is still very little consensus about what a good teacher is (Squires 1999).

Q-methodology holds special promise for those seeking to gain insights into the dimensions of subjective phenomena. This is accomplished by a respondent systematically sorting a set of statements that seek to capture the dimensions under investigation according to given criteria (normally scales or response categories). Most Q-samples contain 40 to 60 
such statements, but they may number less or more (Brown 1986). The statements are validated according to whether the respondents place them in the same categories. The result of a Q-sort, therefore, is a set of statements that have been agreed collectively by a group of respondents. In this sense, the output of a sample of Q-sort tests should be seen as proof of the existence of a cognitive pattern (Thomas and Baas 1992). It plays the part of setting up empirical approaches so that concepts can be validated. The resulting statements then provide a basis for further measurement, often by factor analysis. It should be noted that without submitting Q-results to further study the technique must be seen only as a preliminary methodology (McKeown and Thomas 1988).

In effect, two Q-sorts were used for this study: TAQ (Teaching Ability Q-sort), an 80-item Q-sort to identify common evaluation dimensions of ability, and TKQ (Teacher Knowledge Q-sort), a 60-item sort used to measure perceptions regarding the knowledge base. The items in the sorts were short concise statements culled from existing studies, various books and periodicals, and related to a hidden structure devised from the literature. For the TAQ, the areas of the structure were as follows: concern for students, classroom technique, stimulation, and control. These dimensions of ability were chosen on the basis that they had been frequently used in empirical studies (Sontag 1968; Marsh 1983; Murray 1983).

The study also adopted for testing a list of teacher knowledge dimensions: ways of learning, relation to context of industry, knowledge structure, security of knowledge, relationship to theory, and current versus fundamental knowledge. This was informed by a number of key sources on the kinds of knowledge that inform individuals' expertise (Bruner 1966; Chi, Glaser and Farr 1988; Daley 1999). It should be noted that following the advice of Kerlinger (1966) that statements have to be positive in quality because negative items introduce "implicative" bias in the sorting procedure, items that implied a bad teacher were avoided in both sorts.

A total of 31 subjects took part in the tests. At this stage, the selection procedure of subjects was limited to two criteria; that they were either tourism teachers or students registered on tourism-related programs. All respondents were based at two major universities in the United Kingdom. Evaluations of activities are much more likely to be insightful if the participants know what it is all about. Clearly those directly involved understand the basis and process of evaluation and need to be equipped to evaluate (Squires 1999). In this sense, given the exploratory nature of this research, excluding teachers from the Q-study might have led to loss of important insights in the evaluation. Overall, the sample included 10 teachers, 14 graduate and 7 doctoral students. 
As far as the number of participants is concerned, according to Brown (1986) sample sizes of the range used here are more than adequate for Q-studies of public opinion. As a matter of fact, the number of participants in the majority of previous Q-studies ranges from 20 to 100 people (Tractinsky and Jarvenpaa 1995). This preference of Q-researchers to work with small samples runs counter to conventional wisdom insofar as social scientists tend to regard small samples with suspicion. In this connection, it is important to point out that the purpose of Q-researchers is to explore the subjective meaning that items have for respondents - a task obviously antecedent to ascertaining the numerical incidence and demographic correlates of such opinions (Brown 1986).

To begin the Q-sorting activity, each subject was presented with two decks of numbered stimulus cards. Subjects were asked to sort the items according to a standard set of instructions. For the TAQ these boiled down to: please sort the cards on the basis of whether they represent excellence; ordinary competence; or they are not relevant to either. These types of response categories were chosen because of Elton's (1996) work on the distinction between competence and excellence, which suggests that the first thing to achieve is general competence. Subjects were further instructed to sort the items for the TKQ according to whether in their opinion they represent an expert academic; a novice academic; or they are not relevant to either. In both sorts, the "not relevant to either" option was used because as already indicated the research makes no assumptions about the existence of the dimensions.

For the results, the rules of the procedure followed were that a dimension only exists if at least two statements legitimately describe it and for a statement to be legitimate 60 per cent of the sample must have allocated it to the same category (Hinkin and Schreisheim 1989). This percentage can be seen as similar to a correlation score, which is a major method used for assessing the reliability and validity of a scale. Given the fact that it is very rare to find a 100 per cent agreement among the subjects in sorting procedure, such a high value reduces the risk of overlapping statements with other categories (Ekinci and Riley 1999). At the last stage, a minimum of four statements per dimension should be obtained in order to provide adequate internal consistency (Hinkin, Tracey and Enz 1997).

The output of the Q-sort tests was that of the original 140 statements, 52 (25 for the TAQ and 27 for the TKQ) were found to represent the proposed dimensions under the rules. This gives support to the notion that such dimensions exist (Brown 1986). However, as Ekinci and Riley (1999) suggest, the more times a statement goes through a Q-sort test and meets the statistical criteria, the more confidence the researcher can have in its ultimate performance. For this reason a further Q-sort study with all the qualifying statements and a newly 
generated 55 statements for the TAQ and 33 for the TKQ was carried out with 30 respondents (10 teachers, 20 graduate students). As a result 35 statements qualified with the same rules and these were added to the first bank of statements.

\section{Questionnaire Survey}

Having obtained a sufficient number of statements, the next stage was to transfer a selection of accepted statements to a questionnaire for further testing. In order to ensure enough questions to be of value to the research, but not so many as to be off-putting to respondents, 30 statements were selected for each of the TAQ and TKQ dimensions. For this, all statements that qualified in both rounds of the Q-sorts under the same category were transferred to the questionnaire. This set of items was then complemented by those statements which achieved the highest degree of consensus in the sample in the second Qstudy. As a result of this selection process 15 statements each were used to represent respectively excellence and competence. Similarly, for the TKQ category there were 15 statements for each of the expert and novice categories.

Respondents were asked to respond to statements from the Q-sort, using semantic differential for TAQ and a Likert scale for TKQ. For the purposes of this inquiry the semantic differential operated by putting adjectives of a positive quality at either ends of the scale (excellent/competent). These were similar to the response categories used in the TAQ and in line with the positive nature of the Q-statements. With respect to teacher knowledge, the Likert scale was designed to measure the extent to which respondents agreed that the statements represented the characteristics of an expert. In this case, the Likert scale was preferred over the semantic differential because the uncertainty about the term "novice academic" in the first round of the TKQ meant that its use at one end of the scale might have introduced response bias in that survey participants could perceive the term as being negative. The hidden structure identified above was not revealed.

The selection of respondents involved a mixture of aspects of convenience and maximum variation sampling. Convenience sampling is built upon selections which suit the researcher and which are available by virtue of their accessibility (Clark, Riley, Wilkie and Wood 1998). The data were collected at three different institutions, where the researchers had personal contacts who showed interest in the study and facilitated access. However, subjects were not drawn in the sample simply because they just happened to be available. Rather, the choice of subjects aimed at maximizing the variety of sampled respondents. 
This approach to selecting people or settings purposefully for a study was popularized by Glaser and Strauss (1967) and provides a foundation for the distinct approach to sample design. This provides the researcher with a method by which the variability characteristic of random selection can be addressed, while recognizing that the goal of the study is not generalizability (Maykut and Morehouse 1994). Indeed, the purpose here was not to build a random sample, but rather to select settings and persons that the researchers thought represented the range of experience in the phenomenon under investigation. Questionnaires were distributed and collected in class from 303 students registered in programs of study at the three different institutions: a university established before the 1992 expansion of the university system in the United Kingdom, a university established after 1992, and a university college. Both undergraduate and postgraduate courses were represented, the populations of which covered a range of demographic and educational characteristics.

\section{Study Results}

As far as demographic and other information is concerned, almost half of those sampled (47.2\%) were from the pre-1992 university. Thirty six percent were drawn from the participating university college and $16.8 \%$ from the post-1992 university. The overwhelming majority were studying on programs with tourism in the title. In $90 \%$ of the cases the word "management" also appeared giving an indication that the programmes have an industry specific and employment orientation. Of the sample population, $76.6 \%$ were female, $60.7 \%$ were undergraduates and 51.5\% had English as their first language. Almost two thirds were aged 20 -25 years with $17.8 \%$ under 20 years and $16.2 \%$ over 25 years. Year of study for undergraduates was year one, $21.2 \%$, year two $39.7 \%$, year three $34.8 \%$ and year four $4.3 \%$. All students were registered in full-time programs.

The initial results of responses to the Q-statements formed the basis for a factor analysis. For this the data were entered into a statistical analysis program and a reliability analysis undertaken. The Cronbach Alpha value was .896 for the TAQ scale and .870 for TKQ, both well above the .70 level which is considered to be moderate in studies in education and the social sciences (Nunally 1967). These show good measures of reliability. Product moment correlation coefficients were computed for each data set and the resulting matrices of interitem correlations were inspected to assess the factorability of the scales. A matrix that is factorable should include several sizeable correlations. The expected size depends to some extent on sample size, but if no correlation exceeds .30, use of factor analysis is questionable 
(Tabachnick and Fidell 1996). This analysis for both scales revealed numerous inter-item correlations in excess of .30 and some considerably higher.

The Kaiser-Meyer-Olkin measure of sampling adequacy and Bartlett's test of sphericity were also used to assess the factorability of the scale. The current study obtained a sampling adequacy measure of the .89 for the TAQ data and of the .854 for TKQ, both of which fall in the "meritorious" category of the .80 s (Kaiser 1974). With respect to Bartlett's test of sphericity, the former obtained a value of 3387.532 and the latter scale a value of 2865.514 , both with an associated significance level of .000. The high values obtained for sampling adequacy and the highly significant levels of the test of sphericity provide empirical evidence that the given sets of data are adequate for factor analysis.

Both inter-item correlations matrices were analyzed by the principal factors method and an orthogonal rotation was made. However, the resulting data suggested that for the TAQ items an oblique solution would more nearly satisfy the requirements for simple structure. If simple structure is present, several variables correlate highly with each factor and only one factor correlates highly with each variable (Thurstone 1947). In this way, the simplest possible interpretation can be achieved.

With a cut off .45 for inclusion of a variable, the analysis of the TAQ data yielded two major factors with eigenvalues higher than 3.00, which accounted for $39.2 \%$ of the total variance, plus four smaller factors (Table 1). As regards the two major factors, Factor 1 includes items from two dimensions of the TAQ, which seem to reflect the tendency of a teacher to be systematic, orderly, and to make things clear. This factor is provisionally named "Structural Organization of Knowledge". Factor 2 includes items from the concern for students and stimulation dimensions of the TAQ. The items seem to reflect a teacher's concerned attitude toward issues related with the intellectual curiosity and development. This factor is provisionally named "Person Oriented Intellectual Reinforcement". With respect to the four remaining factors, their interpretation was attempted for exploratory purposes. Given the pioneering nature of this study, it was thought that some interesting findings might emerge from this analysis. However, it should be borne in mind that due to the low eigenvalues and proportion of variance accounted for by these factors, conclusions about the interpretations should not be drawn too quickly or too easily. Factor 3 seems to be primarily about communication behavior. As presented in Table 1, three items loaded on this factor. These suggest a pattern of behavior in which the teacher assumes the role of encouraging students, and in which there is little domination. Perhaps the pattern is best characterized as "Supporting Teacher". The interpretation of Factor 4 is troublesome. Its pattern is set by 
four statements which taken together seem to suggest that it is not substantially related to any specific notion of teaching. For this reason, and because the factor is neither strong nor clear in statistical terms, it eludes confident interpretation.

Table 1. Teaching Ability - Sorted Factor Loadings

\begin{tabular}{|c|c|c|c|}
\hline Factors and their statements & $\begin{array}{c}\text { Factor } \\
\text { Loadings }\end{array}$ & Eigenvalue & $\begin{array}{c}\% \text { of } \\
\text { Variance }\end{array}$ \\
\hline $\begin{array}{l}\text { Factor 1: Structural Organization of Knowledge } \\
\text { The teacher announces the objectives of the lecture at the beginning } \\
\text { The teacher explains to students how their work will be assessed } \\
\text { The teacher connects lectures to reading }\end{array}$ & $\begin{array}{l}.601 \\
.512 \\
.492\end{array}$ & 8.042 & 27.73 \\
\hline $\begin{array}{l}\text { Factor 2: Person Oriented Intellectual Reinforcement } \\
\text { The teacher explores with students new approaches and meanings } \\
\text { The teacher develops students' capacity to think for themselves } \\
\text { The teacher stimulates the intellectual curiosity of students }\end{array}$ & $\begin{array}{l}.637 \\
.548 \\
.521\end{array}$ & 3.328 & 11.5 \\
\hline $\begin{array}{l}\text { Factor 3: Supporting Teacher } \\
\text { The teacher compliments students on their work in front of others } \\
\text { The teacher maintains order without apparent effort } \\
\text { The teacher commends effort on the part of students }\end{array}$ & $\begin{array}{l}.792 \\
.482 \\
.452\end{array}$ & 1.730 & 6 \\
\hline $\begin{array}{l}\text { Factor 4: Indeterminate } \\
\text { The teacher diagnoses students' misunderstandings and tries to represent the } \\
\text { information in a different way } \\
\text { The teacher prepares students for employment } \\
\text { The teacher brings examples from the field } \\
\text { The teacher maintains a friendly atmosphere, but maintains the authority of } \\
\text { the teacher }\end{array}$ & $\begin{array}{l}.540 \\
.508 \\
.490 \\
.466\end{array}$ & 1.433 & 4.94 \\
\hline $\begin{array}{l}\text { Factor 5: Systematic/Orderly Behavior } \\
\text { The teacher carefully times lectures } \\
\text { The teacher keeps everything according to schedule } \\
\text { The teacher corrects spelling } \\
\text { The teacher is consistent in administering discipline } \\
\text { The teacher sets up rules of engagement and sticks to them }\end{array}$ & $\begin{array}{l}.707 \\
.666 \\
.598 \\
.462 \\
.455\end{array}$ & 1.031 & 3.6 \\
\hline $\begin{array}{l}\text { Factor 6: Person Oriented Functional Fixity } \\
\text { The teacher gives more support to those students identified as being less able } \\
\text { to learn independently } \\
\text { The teacher varies teaching approach according to content } \\
\text { When planning lessons, the teacher takes under consideration students' prior } \\
\text { learning }\end{array}$ & $\begin{array}{l}.618 \\
.515 \\
.494\end{array}$ & 1.002 & 3.5 \\
\hline
\end{tabular}

The fifth factor (Factor 5) is perhaps the most interesting finding from the analysis of the four weak factors. This is because despite its disappointing performance in terms of eigenvalue (1.031) and accounted percentage of variance (3.60\%), the factor loadings of the five items are among the highest. But not only are the loadings surprisingly high, they have obvious meaning. They may all be seen as concomitants of a systematic, orderly, businesslike behavior pattern. Thus, this factor is called "Systematic/Orderly Behavior". Factor 6 is the last factor and accounts for the least of the total variance (3.50\%). These items appear to deal with behaviors that denote a concern for students' learning and freedom from functional 
fixity. These notions seem to be expressed by the name "Person-oriented Functional Flexibility".

Factor analysis of the intercorrelations of the teacher knowledge items resulted in the extraction of five factors (Table 2). The first two of these emerged as primary ones, appropriating $34.2 \%$ of the total variance. Factor 1 is contributed to by four items, which seem to be almost wholly related to the extent to which a teacher updates their knowledge. This notion seems to be expressed by the name "Up-to-dateness". Factor 2 appears to reflect the tendencies to be analytical and knowing where to look for something. These seem to converge on what may be called "Secure Base of Fundamental Knowledge".

Table 2. Teacher Knowledge - Sorted Factor Loadings

\begin{tabular}{|c|c|c|c|}
\hline Factors and their statements & $\begin{array}{c}\text { Factor } \\
\text { Loadings }\end{array}$ & Eigenvalue & $\begin{array}{c}\% \text { of } \\
\text { Variance }\end{array}$ \\
\hline $\begin{array}{l}\text { Factor 1: Up-to-Dateness } \\
\text { Has main aim of getting up-to-date information out of the journals } \\
\text { Has sufficient confidence in their knowledge to invite and answer questions } \\
\text { in class } \\
\text { Reviews and modifies knowledge on the basis of new developments in the } \\
\text { field } \\
\text { Uses examples from the tourism industry }\end{array}$ & $\begin{array}{l}.677 \\
.656 \\
.628 \\
603\end{array}$ & 6.925 & 23.1 \\
\hline $\begin{array}{l}\text { Factor 2: Secure Base of Fundamental Knowledge } \\
\text { Reads research reports and more informal studies } \\
\text { Is aware of the key developments in the field } \\
\text { Has a good knowledge of the sources of information about the industry } \\
\text { Is able to set and solve problems by applying concepts and techniques } \\
\text { Is sufficiently confident to discard many of the theories that are fashionable } \\
\text { at the time }\end{array}$ & $\begin{array}{l}.629 \\
.609 \\
.568 \\
.526 \\
.458\end{array}$ & 3.317 & 11.1 \\
\hline $\begin{array}{l}\text { Factor 3: Academic Orientation } \\
\text { Uses alternative representations of subject matter } \\
\text { Constructs subject matter as a web of central interconnected concepts } \\
\text { Understands the limitations of theory } \\
\text { Appreciates the corrigible and temporary state of knowledge }\end{array}$ & $\begin{array}{l}.674 \\
.612 \\
.485 \\
.459\end{array}$ & 1.689 & 5.63 \\
\hline $\begin{array}{l}\text { Factor 4: Training Orientation } \\
\text { Emphasizes that one way is correct } \\
\text { Sees the subject matter as existing exclusively in one conceptual framework } \\
\text { Favors one concept or theory to the exclusion of others } \\
\text { Relies only on facts }\end{array}$ & $\begin{array}{l}.642 \\
.571 \\
.554 \\
.492\end{array}$ & 1.370 & 4.6 \\
\hline $\begin{array}{l}\text { Factor 5: Indeterminate } \\
\text { Has direct experience of the tourism industry } \\
\text { Gets to the academic journals on a regular basis } \\
\text { Is able to explain one idea in many different ways }\end{array}$ & $\begin{array}{l}.677 \\
.548 \\
.489\end{array}$ & 1.246 & 4.2 \\
\hline
\end{tabular}

As regards the three remaining factors, in much the same way as in the case of the TAQ, their interpretation was pursued for exploratory purposes. Factor 3 represents a set of deep approaches towards the subject matter. It may be described as "Academic Orientation". In some respects, Factor 4 seems to contradict the pattern of Factor 3. The four items loading 
on this factor seem to suggest a surface approach towards, and engagement with, the subject matter. Perhaps this pattern is best characterized as "Training Orientation". Factor 5 is the last factor and accounts for the least of the total variance (4.2\%). Unfortunately these items do not seem to be related to any specific notion that would allow interpretation. The factor is therefore considered to be indeterminate.

\section{CONCLUSION}

These results from the student's responses contain elements that are disappointing and predictable but at the same time they also identify some important messages. The fact that the hidden structure did not emerge more clearly from the fieldwork findings is in some ways disappointing. This is all the more so in light of the extensive review of the literature and two rounds of the Q-sort. There is an important lesson here that the Q-sort, on its own, can only be a preliminary stage. It has helped clarify some of the dimensions of the subjective judgements, and in this study it is undoubtedly associated with the achievement of the high alpha values, but in the end this can only provide the starting point for the fieldwork.

However, notwithstanding the poor fit with the hidden structure, the two dominant dimensions for the final results, both for knowledge and ability, do point to some important ingredients for what makes effective teaching, at least from the perspective of the students. What appears to be of key importance, as far as ability is concerned, is the way in which the teacher organizes the classes and the ways in which they challenge thinking. The importance of organization behaviour is also highlighted in the pattern of the "Systematic/Orderly Behaviour" factor. For the dimension relating to knowledge the important issues are being up-to-date and confident. Within these it is worth noting a specific characteristic. Specific statements relating to "new developments in the field", "examples from the tourist industry", "key developments in the field" and "sources of information about the industry" all point to an emphasis on the industry specific aspect of their studies. There is clearly a recognition by students of the need for their teachers to be up-to-date. Many of the findings are not particularly surprising. It is not unexpected that students rely on the teachers to organize their material or look to them to stimulate their thinking. Nor, for what are mainly designed as industry specific courses, is it in any way odd that they should expect current information about tourism. However, the statements included in the top two factors for each dimension suggest that the students' views do extend beyond simple vocationalism. Statements about "connects lectures to reading", "explores ... new approaches and meanings", "develops ... capacity to think for themselves", "stimulates intellectual curiosity", "reviews and modifies 
knowledge", "confidence to discard ... theories" all suggest a deeper level of understanding. They are clearly not at university solely for industry specific relevance but are also seeking a deeper set of experiences.

The implications of embracing this wider conception of education and the values which it presupposes are considerable. In particular, there are implications for the content of the curriculum and its organization, for teaching, and for the student experience. For courses, the space - intellectual and practical - which is called for by the findings of this study, points to significant levels of autonomy and independence in both thought and action. This implies an ethos in which students are encouraged to find their own voices and are invited to claim responsibility for their own learning. It implies that teachers should not teach that $\mathrm{x}$ or $\mathrm{y}$ is the case as such, but put it forward as a credible hypothesis for real consent. This, in turn, suggests that formal didactic teaching should be kept to a minimum, with sessions containing real interaction. Where lectures have to be given in the traditional form of continuous unbroken speech (i.e. due to resource constraints), they should be carefully thought through so that they do offer overviews to topics from a critical standpoint, as well as attempting to challenge thinking.

This broader notion of education can also be supported by the use of simulated or actual professional situations, in which the repertoire of technical knowledge can be extended, as well as by offering opportunities to develop critical skills. But there are also questions to be asked of curricula about the extent to which theory and practice are really integrated; the degree to which they are genuinely interdisciplinary, intertwining (as the demands of professional life in the industry call for) different disciplinary perspectives; and whether there are opportunities for the very real value and ethical questions to be explored (to which the graduate or novice professional is going shortly to be exposed) or whether the professional role is simply presented as a technical one, of putting skills and technologies in operation according to a set of well-defined rules (Tribe 2002a, 2002b).

It will be apparent from this discussion that teachers have definite and considerable responsibilities. In an education for immediate employment or for the transmission of simple facts and truths, the responsibilities of the teacher are definite but limited: on the one hand, to bring students to a mastery of identified technical skills and, on the other hand, to enable them to live comfortably in disciplinary territories. In an education for life, the responsibilities are expanded. In essence, it is that of turning a cohort of students into a learning community, by stimulating their intellectual abilities (person oriented intellectual reinforcement) and encouraging them to claim their independence and develop their critical 
consciousness. In so doing, the teacher has to establish some sense of where the learning is going, in terms of outcomes and priorities (structural organization of knowledge). They also have special responsibilities to be fully on the inside of their disciplinary calling: they should have a secure base of fundamental knowledge but also keep current with information about tourism (up-to-dateness).

In many ways the development of knowledge over the past few decades, particularly by social scientists, combined with the practical elements of tourism put the subject in an excellent position to provide a strong and demanding education. The important questions now are the extent to which those involved in the classroom engage the students not only in understanding the theoretical and explanatory frameworks that have been developed but also get them to challenge them, to consider them in practical settings and at the fullest extent to revise or even overturn them. The classroom and what goes on in the classroom is vital in this. The significance of this for the work of social scientists is considerable. The development of knowledge, from a social science perspective, has been great, but its full effect for the next generation of scholars and practitioners is sadly diminished if it is not brought effectively into the classroom. The role of the teacher here is paramount not only in understanding but also in having the ability to communicate in ways that extend understanding.

To put it sharply, being a teacher of the kind envisaged here is a complicated matter. It entails engaging in a set of transactions with, and encouraging development in, a group of students, that will enable them to find their own voices, to become more fully themselves, and to develop within frameworks of understanding made available to them that extend beyond the business aspects. It would be wrong to infer from this that higher education should be dismissive about its vocational elements or the teaching of skills and development of capabilities in response to individual and social requirements in pursuit of learning and knowledge for work effectiveness. Nor is it suggested that business approaches are inappropriate or that they cannot exist alongside more philosophical, creative or abstract roles. The important point is that these should not be the totality of its responsibilities or commitments. 


\section{REFERENCES}

Airey, D.

2005 Tourism Education: From Practice to Theory. In The Role of Education in Quality

Destination Management, Proceedings of the WTO Education Council Conference, pp.

9-16. Madrid: World Tourism Organization.

Airey, D., and S. Johnson

1998 The Profile of Tourism Studies Degree Courses in the UK: 1997/98. London: National Liaison Group.

1999 The Content of Tourism Degree Courses in the UK. Tourism Management 20:229235.

2000 Tourism Degree and Postgraduate Level Courses in the UK - Dimensions

Characteristics and Content. London: Unpublished Report to the British Travel Educational Trust, 47 pages.

Archer, B.

1977 Tourism Multipliers: The State of the Art. Cardiff: University of Wales Press.

Barnett, R.

1990 The Idea of Higher Education. Buckingham: Open University Press.

Brockett, R., and R. Hiemstra

1991 Self-direction in Adult Learning: Perspectives on Theory, Research and Practice.

London: Routledge.

Brown, S.

1986 Q Technique and Method: Principles and Procedures. In Advances and Applications

in Research Methods, W. Berry and M. Lewis-Beck, eds., pp. 57-76. London: Sage..

Bruner, J.

1966 Toward a Theory of Instruction. London: Oxford University Press.

Butler, R.

1980 The Concept of a Tourist Area Life Cycle of Evolution: Implications for

Management and Resources. Canadian Geographer 24:5-12.

Candy, P.

1991 Self-direction for Lifelong Learning: A Comprehensive Guide to Theory and

Practice. San Francisco: Jossey Bass.

Carr, D.

1994 Educational Enquiry and Professional Knowledge: Towards a Copernican Revolution. Educational Studies 20(1):33-54. 
Cashin, W.

1995 Student Ratings of Teaching: The Research Revisited. IDEA paper No 32. Manhattan: Center for Faculty Evaluation and Faculty Development, Kansas State University.

Centra, J.

1994 The Use of the Teaching Portfolio and Student Evaluations for Summative Evaluation. Journal of Higher Education 65:555-570.

Chi, M., R. Glaser, and M. Farr

1988 The Nature of Expertise. Hove: Lawrence Erlbaum.

Clark, M., M. Riley, E. Wilkie, and R. Wood

1998 Researching and Writing Dissertations in Hospitality and Tourism. London: International Thomson Business Press.

Cohen, E.

1972 Toward a Sociology of International Tourism. Social Research 39:164-182.

Daley, B.

1999 Novice to Expert: An Exploration of How Professionals Learn. Adult Education Quarterly 49(4):133-147.

Dunkin, M., and B. Biddle

1974 The Study of Teaching. New York: Holt, Rinehart and Winston.

Ekinci, Y., and M. Riley

2001Validating Quality Dimensions. Annals of Tourism Research 28:202-223.

Elton, L.

1996 Criteria for Teaching Competence and Teaching Excellence in Higher Education. In

Evaluating Teaching Quality in Higher Education, R. Aylett and K. Gregory, eds., pp.

33-41. London: Falmer Press.

Fenstermacher, G.

1986 Philosophy of Research on Teaching: Three Aspects. In Handbook of Research on Teaching ( $3^{\text {rd }}$ edition), M. Wittrock, ed., pp. 37-49. New York: Macmillan.

Glaser, B., and A. Strauss

1967 The Discovery of Grounded Theory: Strategies for Qualitative Research. Chicago: Aldine.

Graburn, N.

1983 The Anthropology of Tourism. Annals of Tourism Research 10:9-33.

Hinkin, T., and C. Schriesheim 
1989 Development and Application of New Scales to Measure the French and Raven (1959) Bases of Social Power. Journal of Applied Psychology 74:561-567.

Hinkin, T., Tracey, J., and C. Enz

1997 Scale Construction: Developing Reliable and Valid Measurement Instruments.

Journal of Hospitality and Tourism Research 21(1):100-121.

Hirst, P.

1973 What is Teaching? In The Philosophy of Education, R. Peters, ed., pp. 163-177. Oxford: Oxford University Press.

Holden, A.

2005 Tourism Studies and the Social Sciences. London: Routledge.

Jackson, $\mathrm{P}$.

1986 The Practice of Teaching. New York: Teachers College Press.

Kaiser, $\mathrm{H}$.

1974 An Index of Factorial Simplicity. Psychometrika 39:31-36.

Kerlinger, F.

1966 Attitudes Toward Education and Perceptions of Teacher Characteristics: A Q-study.

American Educational Research Journal 3:159-168.

1992 Foundations of Behavioural Research ( $3^{\text {rd }}$ ed.). New York: Holt, Rhinehart and Winston.

MacCannell, D.

1973 Staged Authenticity: Arrangements of Social Place in Tourist Setting. American Journal of Sociology 79:586-603.

1976 The Tourist. London: Macmillan.

Marsh, $\mathrm{H}$.

1983 Multidimensional Ratings of Teaching Effectiveness by Students from Different

Academic Settings and Their Relation to Student/Course/Instructor Characteristics. Journal of Educational Psychology 75:150-166.

1987 Students' Evaluation of University Teaching: Research Findings, Methodological

Issues, and Directions for Future Research. International Journal of Educational Research 11:253-338.

Maykut, P., and R. Morehouse

1994 Beginning Qualitative Research: A Philosophic and Practical Guide. London:

Falmer Press.

McKeown, B., and D. Thomas 
1988 Q-Methodology. Newbury Park: Sage.

Mount, D., and M. Sciarini

1999 IPI and DSE: Enhancing the Usefulness of Student Evaluation of Teaching Data.

Journal of Hospitality and Tourism Education 10(4):8-13.

Murray, $\mathrm{H}$.

1983 Low-inference Classroom Teaching Behaviours and Student Ratings of College

Teaching Effectiveness. Journal of Educational Psychology 75(1):138-149.

Nunally, J.

1967 Psychometric Theory. New York: McGraw-Hill.

Nykiel, R.

1999 Effective Teaching Techniques for Alternative Delivery Programmes. Journal of

Hospitality and Tourism Education 11(1):8-11.

Pearce, D.

1987 Tourism Today: A Geographical Analysis. Harlow: Longman.

Ramsden, $\mathrm{P}$.

1991 A Performance Indicator of Teaching Quality in Higher Education: The Course

Experience Questionnaire. Studies in Higher Education 16:129-150.

Sexton, D., Snyder, P., Wadsworth, D. Jardine, A., and J. Ernest

1998 Applying Q Methodology to Investigations of Subjective Judgements of Early

Intervention Effectiveness. Topics in Early Childhood Special Education 18(2):95-107.

Shulman, L.

1987 Knowledge and Teaching: Foundations of the New Reform. Harvard Educational

Review 57(1):1-22.

Smith, B.

1983 Some Comments on Educational Research in the Twentieth Century. Elementary

School Journal 83:488-492.

Smith, V.

1977 Hosts and Guests: The Anthropology of Tourism. Philadelphia: University of Pennsylvania Press

Sontag, M.

1968 Attitudes Toward Education and Perception of Teacher Behaviors. American

Educational Research Journal 5:385-402.

Squires, G.

1999 Teaching as a Professional Discipline. London: Falmer Press. 
Stephenson, W.

1953 The Study of Behaviour: Q-technique and its Methodology. Chicago: University of Chicago Press.

Tabachnick, B., and L. Fidell

1996 Using Multivariate Statistics (third edition). New York: Harper Collins.

Thomas, D., and L. Baas

1992 The Issue of Generalization in Q-Methodology: Reliable Schematics Revisited. Operand Subjectivity 16(1):18-36.

Thurstone, L.

1947 Multiple-factor Analysis. Chicago: University of Chicago Press.

Tractinsky, N., and S. Jarvenpaa

1995 Information Systems Design Decisions in a Global Versus Domestic Context.

Management Information Systems Quarterly 19:507-534.

Tribe, J.

1997 The Indiscipline of Tourism. Annals of Tourism Research 24:628-657.

2000 Balancing the Vocational: The Theory and Practice of Liberal Education in Tourism.

Tourism and Hospitality Research 2(1):9-25.

2002a Research Trends and Imperatives in Tourism Education. Acta Turistica 14(1):6181.

2002b The Philosophic Practitioner: A Curriculum for Tourism Stewardship. Annals of Tourism Research 29:338-357.

Tribe, J., and D. Airey

2007 Developments in Tourism Research. Oxford: Elsevier.

Urry, J.

1990 The Tourist Gaze. London: Sage.

Wilson, S., Shulman, L., and A. Richert

1987 “150 Different Ways of Knowing”: Representations of Knowledge in Teaching. In

Exploring Teachers' Thinking, J. Calderhead, ed., pp. 104-124. London: Cassell.

Winne, P., and R. Marx

1977 Reconceptualising Research on Teaching. Journal of Educational Psychology 69:668-678. 